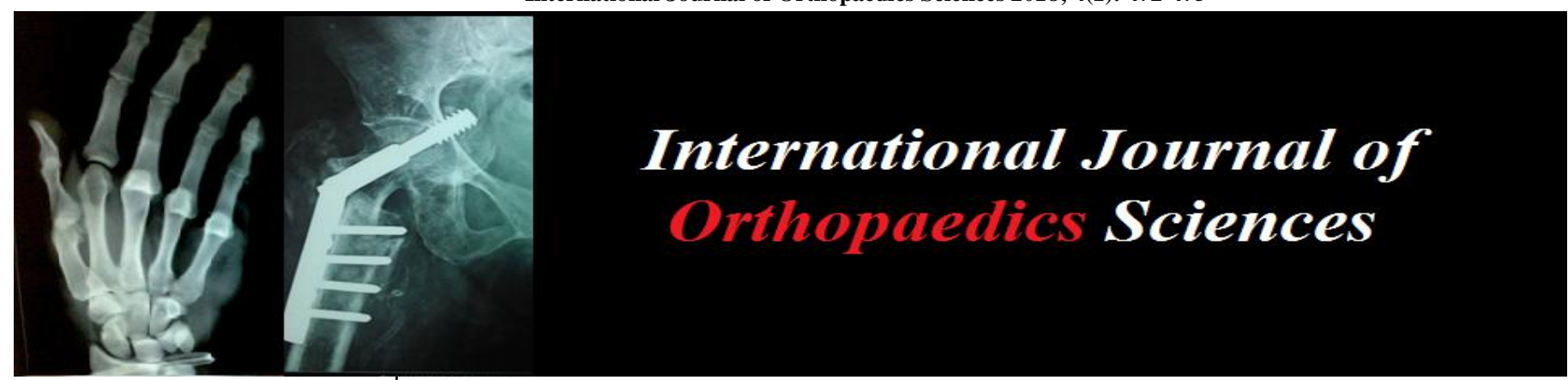

ISSN: $2395-1958$

IJOS 2018; 4(1): 472-475

(C) 2018 IJOS

www.orthopaper.com

Received: 20-11-2017

Accepted: 21-12-2017

Dr. Tushar Ranjan Dalei

Assistant Professor, Department of Orthopaedics, VIMSAR,

Burla, Sambalpur, Odisha, India

Dr. Braja Sundar Sahoo

Associate Professor, Department

of Orthopaedics, VIMSAR,

Burla, Sambalpur, Odisha, India

Dr. BN Mohapatra

Professor, Department of

Orthopaedics, PRM Medical

College, Baripada, Odisha, India

\section{Evaluation of treatment of diaphyseal fracture of humerus: Dynamic compression plate versus interlocking nail: A prospective randomized controlled study}

\author{
Dr. Tushar Ranjan Dalei, Dr. Braja Sundar Sahoo and Dr. BN \\ Mohapatra
}

DOI: https://doi.org/10.22271/ortho.2018.v4.i1g.70

\begin{abstract}
Fracture shaft of the humerus is a common injury in orthopaedic practice. Conservative management with plaster gives good result but this method cannot be applied in situations which necessitates internal fixation. There always a question arises which kind of implant to be used for surgical intervention. A prospective comparative study for the management of acute diphyseal humeral shaft fractures with dynamic compression plate and antegrade interlocking nail fixation was undertaken over a period of three years. In each category Twenty five patients had undergone above implant fixation after considering the inclusion and exclusion criteria. Rate and time of union, functional scoring criteria (ASES) and complication rate were used for postoperative assessment with an average follow-up period of one year. A higher rate of union with excellent to good functional outcome was seen with the plating group in our series.
\end{abstract}

Keywords: Diaphyseal humerus fracture, Dynamic compression plate \& Interlocking nail, Union and functional outcome (ASES score)

\section{Introduction}

Diaphyseal fracture of humerus is a common entity accounts for $3 \%$ to $5 \%$ of all fractures. Most closed fractures of humeral shaft can be treated conservatively with union rate more than $90 \%{ }^{[1-6]}$. However prolonged immobilization ${ }^{[7,8]}$ unstable fractures (spiral/long oblique), comminuted fractures, segmental fractures, pathological fractures, open fractures, fractures with radial nerve injury or vascular injury, multiple injury are not ideal for conservative management ${ }^{[5,9-11]}$. Failure to maintain the adequate reduction with time is also an indication for surgery ${ }^{[12]}$.

Surgical stabilization can be achieved with plates \& screws, intramedullary nails or external fixators ${ }^{[13]}$. External fixator is generally reserved for compound fracture following high energy gunshot wounds, fractures with significant soft tissue injuries. Both plating and intramedullary nailing have their own anatomical and biomechanical advantages and disadvantages.

In view of various modalities of management with controversies regarding their use, it is quite difficult to select a right implant for internal fixation of fracture shaft of humerus. Thus the purpose of this prospective study is to compare the results of plates and intramedullary nails in the treatment of humeral shaft fractures to determine the best fixation devise in current scenario.

\section{Materials and methods}

\subsection{Subjects}

Fifty-five patients with informed consent having acute humeral shaft fractures were treated with either plating or interlocking nailing procedures over a period of three years (2010 to 2013) with average follow-up period of one year (range 10-24 months). 5 patients were lost during follow up and they were excluded from the study. A prospective randomisation attempt was made by allocating each patient to either of the groups using a sealed envelope technique.
Dr. Tushar Ranjan Dalei

Assistant Professor, Department

of Orthopaedics, VIMSAR,

Burla, Sambalpur, Odisha, India 
Adult patients with fracture of humeral shaft within $3 \mathrm{~cm}$ proximal to the olecranon fossa to $2 \mathrm{~cm}$ distal to the surgical neck of the humerus were included in the study. Polytraumatised patients, unacceptable reduction following closed reduction, compound fracture of grade $1 \& 2$, fracture associated with radial nerve palsy were included in the study. Pathological fractures, segmental fractures were excluded from the study.

\subsection{Operative details}

Most of the patients were operated within a week of trauma with an average time interval from injury to surgery was 4.66 days. In 25 cases, DCP was done through an anterolateral or posterior approach. The plates were AO $4.5 \mathrm{~mm}$ DCP plates, with the length depending upon the type of fracture. Minimum 3 screws on either side of fracture was fixed. Intramedullary interlocking nail was used in 25 cases. Antegrade technique was used in all cases. Nails were inserted following reaming and locked up screws both proximally and distally.

Almost all except one case of plating were operated under brachial anesthesia and most of the cases of nailing were done under GA. The commonest diameter of nail used was $7 \mathrm{~mm}$ (52 \%) followed by $6 \mathrm{~mm}(36 \%)$ and $8 \mathrm{~mm}(12 \%)$ respectively. Nail size $26 \mathrm{~cm}$ was most commonly used (40 $\%)$ followed by $24 \mathrm{~cm}(28 \%), 22 \mathrm{~cm}(24 \%), 20 \mathrm{~cm}$ and 28 $\mathrm{cm}$ (each $4 \%$ ) respectively. Most commonly 7 hole broad DCP was used in plating procedure $(48 \%)$. Lag screw for reduction was used in $28 \%$ cases.

\subsection{Follow up}

Subsequently patients were followed up clinically and radiologically at $3 \mathrm{wk}, 6 \mathrm{wk}, 3$ month, 6 month and 1yr. Data were collected by verbal communication, clinical examination and radiographic features. Both functional and anatomical assessment was done. The outcomes were assessed in terms of functional outcome using the American Shoulder and Elbow Surgeons' Score, ability to return to previous jobs, union time, union rate and the incidence of complications. The results were analyzed statistically using the SPSS software version 16 with $\mathrm{p}$ value less than 0.05 to be significant.

\section{Results}

\subsection{Demographic details}

Demographic profile of the study in table 1 .

Table 1: Clinical details of the patients. ( $\mathrm{SD}=$ Standard Deviation)

\begin{tabular}{|c|c|}
\hline Mean age(yrs) & $39.78(\mathrm{SD}=13.869)$ \\
\hline Range & $19-72$ \\
\hline Male: Female & $34: 16$ \\
\hline Right : left & $28: 22$ \\
\hline Mode of injury & \\
\hline RTA & $52 \%$ \\
\hline Fall & $30 \%$ \\
\hline Others & $18 \%$ \\
\hline
\end{tabular}

\subsection{Intraoperative findings}

Time taken for surgery was more in plating (mean $90.2 \mathrm{~min}$, $\mathrm{SD}=9.946$ ) compared to nailing (mean 62.6min, $\mathrm{SD}=$ 17.919). This comparison is statistically significant with twotailed $\mathrm{P}$ value is $<0.0001$, considered extremely significant, $\mathrm{t}=$ 7.992 with 24 degrees of freedom.

Operative blood loss in plating (mean $154.16 \mathrm{ml}, \mathrm{SD}=$ 13.924) was more compared to nail group (mean $29.8, \mathrm{SD}=$ 15.308) and this comparison is statistically significant. $(p<0.0001)$. Intraoperative Radial nerve injury was most common complication in plating, where as in nailing it was opening of fracture site during difficulty in nail insertion. (Table 2 showing intraoperative complications)

Table 2: Showing intraoperative complications

\begin{tabular}{|c|c|c|}
\hline Complication & Plating & Interlocking nail \\
\hline Distraction & -- & $02(8 \%)$ \\
\hline $\begin{array}{c}\text { Conversion to OR from closed } \\
\text { reduction }\end{array}$ & -- & $04(16 \%)$ \\
\hline Difficulty in locking & -- & $02(8 \%)$ \\
\hline Iatrogenic fracture & $01(4 \%)$ & $02(8 \%)$ \\
\hline Drill bit broken & $01(4 \%)$ & -- \\
\hline Radial nerve injuries & $03(12 \%)$ & $01(4 \%)$ \\
\hline Reamer broken & -- & $01(4 \%)$ \\
\hline
\end{tabular}

\subsection{Union and functional outcome}

There was no tenderness at fracture site at the end of 2 month in $88 \%$ cases in both the groups, (mean for plating 1.46 month, $\mathrm{SD}=0.676 \&$ mean for nailing $1.58, \mathrm{SD}=0.6874$ ). This comparison is considered to be significant with two tailed $\mathrm{p}$ value 0.04072 .

In one case of plating there was no callus at all since the point of fixation; finally it ends up with non-union. Callus appearance was most commonly seen in $2^{\text {nd }}$ month in both the group.

Three cases from each group did not show any sign of complete radiological or clinical evidence of union. They were ended with delayed union and non-union. Excluding these cases in plating group, fracture of most of the patients $(95 \%)$ united within $<16$ weeks. The average time of union was 13.09 weeks, $\mathrm{SD}=1.743$. In nailing group, fracture of $73 \%$ of the patients united in less than 16 weeks, and $95 \%$ of patients united within $20^{\text {th }}$ weeks. The average union time being 15.5 weeks, $\mathrm{SD}=2.54$.

$88 \%$ of our patients in plating and $76 \%$ of nailing group had excellent external rotation of more than 45 degree. One case of either group had external rotation less than $20^{\circ}$. However elbow range of motion in both groups was excellent. Mean American Shoulder and Elbow Surgeons (ASES) score in plating group was $46.88(\mathrm{SD}=4.693)$ compared to nailing group was $45.72(\mathrm{SD}=4.258) .80 \%$ of the patients in plating group had excellent upper limb functional status at the end of the treatment, compared to $56 \%$ of the patients in nailing group with ASES 47-52. Only $4 \%$ of both the group had ASES 32-36 which implies fair functional status of upper limbs. The two-tailed $\mathrm{P}$ value is 0.3646 , considered not significant.

\subsection{Post-operative complications}

Average post-operative complication (table 3) in nailing group was more than that of plating group, with a mean in nailing group $1.4(\mathrm{SD}=0.9661)$ and in plating group $1.0(\mathrm{SD}=$ $0.8165)$.

Table 3: Showing post op complications

\begin{tabular}{|c|c|c|}
\hline & Plating & Interlocking nail \\
\hline Superficial Infection & $02(8 \%)$ & $01(4 \%)$ \\
\hline Deep infection & $02(8 \%)$ & $01(4 \%)$ \\
\hline Delayed union & $01(4 \%)$ & $02(8 \%)$ \\
\hline Non-union & $02(8 \%)$ & $01(4 \%)$ \\
\hline Radial nerve palsy (not recovered) & $01(4 \%)$ & $01(4 \%)$ \\
\hline Implant failure & $01(4 \%)$ & $01(4 \%)$ \\
\hline Shoulder pain & 00 & $03(12 \%)$ \\
\hline Shoulder stiffness & 00 & $03(12 \%)$ \\
\hline Elbow stiffness & $01(4 \%)$ & 00 \\
\hline Screw breakage & 00 & $01(4 \%)$ \\
\hline
\end{tabular}




\section{Discussion}

Different studies ${ }^{[12,14-16]}$ on diaphyseal fracture of humerus showed the commonest age group affected are $3^{\text {rd }}$ and $4^{\text {th }}$ decade with a male ${ }^{[12,15,16,17]}$ predominance. Right side is ${ }^{[12,}$ $13,18,19]$ affected more often than the left. This age group represents the actual earning period in the life time of an individual. Due to early mobilization following injury these patients gain full range of movement with minimal loss of productivity. RTA followed by fall is the major leading cause of such injuries ${ }^{[12,15,16,20]}$. Polytrauma is the leading cause of such morbidity followed by isolated compound fracture and unstable reduction in conservatively managed patients ${ }^{[19,21]}$. In our study pre-existing radial nerve palsy was seen in 7 cases $(14 \%)$. Except one case $(02 \%)$ all recovered within 6 month. In that case, on exploration nerve was found to be lacerated by the hook of the distal segment. This case did not recover till $1 \mathrm{yr}$ and was managed by tendon transfer. Lin et al. ${ }^{[19]}$ in their study found 4 cases $(21 \%)$ of nerve palsy, from which 3 cases recovered completely. Similarly Flinkkila et al. ${ }^{[22]}$ in their study described 5 cases required nerve exploration out of 10 cases $(08 \%)$ of pre-existing nerve palsy.

Average blood loss was more in the plating group. Mohammad Iqbal et al. ${ }^{[13]}$ found similar loss, where average blood loss was $200 \mathrm{ml}$ in plating group compared to nail group $10-20 \mathrm{ml}$. Iatrogenic radial nerve palsy is seen in different studies ${ }^{[4,12,15-17]}$. In our series we had 4 postoperative cases of radial nerve palsy (16\%). 3 cases $(12 \%)$ in plating group and 1 in nailing group. All injuries in plating group were neuropraxia type and eventually recovered completely within 6 month post-operatively. Palsy in the nailing group did not recover even after $1 \mathrm{yr}$. This was associated with LewisHolostein fracture [26]. EMG and Nerve conduction study revealed complete nerve palsy. Finally it was treated by tendon transfer. In plating, due to wide dissection at the fracture site, there is higher chance of damage to the radial nerve because of stretching. Iatrogenic fracture was encountered during surgery ${ }^{[4,12,15-17]}$. We encountered three cases $(12 \%)$ of intraoperative fracture comminution but this did not affect fracture healing and all the fractures united well within four months of period.

A higher rate of excellent to good results with a tendency of early union was seen in plating $(75 \%$ in $<16 \mathrm{wks})$ than in interlocking nailing group ( $50 \%$ in $<16 \mathrm{wk})$. Union time in our series is comparable to Singsetty et al. ${ }^{[23]}$ and Garnal Hosny et al. ${ }^{[20]}$ study. In other series union time in nailing is better than plating ${ }^{[12,16,17]}$.

Union rate in both the group is similar to other study ${ }^{[12,16,17]}$. In our study, the two tailed $\mathrm{p}$ value was 0.0008 , considered to be extremely significant. In spite of extensive stripping of periostium and drainage of fracture haematoma time of union in plating group is earlier. This may be attributed to its rigid dynamic compressive fixation. Union time of both the group is also comparable to conservative mode of treatment, but here the patient is able to use the arm without external splintage so that it helps in preventing osteoporosis, muscle atrophy, joint stiffness and limb oedema.

Functional outcome as measured by ASES score favours plating in our series, though the difference is not statistically significant $(\mathrm{p}=0.83)$ similar to other study ${ }^{[15,17,20]}$. In nailing group ASES score was poor related to shoulder morbidity due to antegrade nailing. In a meta-analysis by Bhandari et al. ${ }^{\text {[24] }}$ reported that plate fixation may reduce the risk of shoulder impingement but the cumulative evidence remained inconsistent and that a larger trial might be needed to confirm the findings.
Shoulder impingement and stiffness is a common entity in nailing group [12, 15-17, 23, 25]. The causes of stiffness are protrusion of nail at the entry point, damage to the rotator cuff, inadequate removal of bone debris after nailing from the entry point, adhesive capsulitis and lack of patient's cooperation with the postoperative physiotherapy regimen. The percentage of impingement is less in our series (12\%). This might be due to the reason that proximal tips of the nails were counter-sunked into the head of humerus. Impingement occurred because of lack of experience with this type of nailing in initial phase and this complication was minimized later on. In nailing, residual fracture site distraction can lead to increased risk of delayed union/non-union, whereas in plating higher rate of nonunion is due to excessive periosteal stripping, loss of biological substances etc ${ }^{[15-17,23,25]}$. In our series three cases from each group had gone for non-union and delayed union, out of which one in each group was infected non-union, which were treated with implant removal, debridement, insertion of vancomycin impregnated PMMA beads. Later these cases were revised by plating and bone grafting once the infection was settled.

Limitation of our study includes short term follow up with small number of patients. We believe that a larger sample size with a longer period of follow-up may draw a clear comparison between the two.

\section{Conclusion}

In acute diaphyseal humerus fracture no single treatment option is superior in all circumstances and each case has to be individualized. Plating has shown to have overall better results as compared to the interlocking nail clinically, functionally, radiologically with shorter union time and minimal complications. However there appears to be no significant difference in both the groups with respect to functional outcome.

\section{Acknowledgement}

No benefits or funds were received in support of this study. All authors report nil conflicts of interest.

\section{References}

1. Boehler L. Conservative treatment of fresh closed fractures of the shaft of the humerus. J Trauma. 1965; 5:464-8.

2. Charnley J. The closed treatment of common fractures. Churchill Livingstone, 3rd ed. Edinburgh-LondonNewYork, 1974.

3. Jupiter JB, Van Deck M Ununited humeral diaphyses. J Shoulder Elbow Surg. 1998; 7:644- 653.

4. Gregory JR PR. Fractures of the shaft of the humerus. In: Buchholz RW \& Hecker JD Rockwood and Green's Fractures in adults. Lippincott Williams \& Wilkins, Philadelphia, 2001, 973-996

5. Sarmiento A, Zaqorski JB, Zych GA. Functional bracing for the treatment of fractures of the humeral diaphysis. JBJS Am. 2000; 82(4):478-486.

6. Sarmiento A, Latta LL. Functional fracture bracing $\mathbf{J}$ AAOS 1999; 7(1):66-75.

7. Rommens PM, Verbruggen J, Bross PL. Retrograde locked nailing of humeral shaft fractures - a review of 39 patients. JBJS, Vol-77-BNo.1, 1995, 84-89.

8. Ulrich C. Non-operative management and selection of treatment method for humeral diaphyseal fractures. In: Flatow E \& Ulrich C (eds) Humerus. ButterworthHeinemann, 1996b, 144-155.

9. Pollock FH, Drake D, Bovill EG et al. Treatment of 
radial neuropathy associated with fractures of the humerus. J Bone Joint Surg Am. 1981; 63(2):239-243.

10. Bell MJ, Beauchamp CG. The results of plating in humeral shaft fractures in patients with multiple injuries, The Sunnybrook Experience. J Bone Joint Surg Br. 1985; 67(2):293-296.

11. Hegelmaier C, Von Aprath B. Plate osteosynthesis of the diaphyseal humerus shaft. Indications-risks-results. Aktuelle Traumatol 1993; 23(1):36-42.

12. Kesemenli CC, Subasi M et al. Treatment of humeral diaphyseal non-union by interlocked nailing and autologous bone grafting. Acta OrthopBelg 2002; 68(5):471-475.

13. Mohammad Iqbal et al. A Comparative Study of Treatment of Humeral Shaft Fractures using Interlocking Nail vs. AO Dynamic Compression Plate Fixation. 2011, 17(2).

14. Raghavendra S, Bhalodiya HP. Internal fixation of fractures of the shaft of the humerus by dynamic compression plate or intramedullary nail: A prospective study. Indian J Orthop. 2007; 41(3):214-218

15. Mc Cormack RG, Brien D, Buckley RE et al. Fixation of fractures of the shaft of the humerus by dynamic compression plate or intramedullary nail. A prospective randomised trial. J Bone Joint Surg [Br] 2000; 82(3):336-339.

16. Chapman JR, Henley MB. Randomized prospective study of humeral shaft fracture fixation: Intramedullary nails versus plates. J Orthop Trauma 2000; 14:162-166.

17. Changulani M, Jain UK, Keswani T. Comparison of the use of the humerus intramedullary nail and dynamic compression plate for the management of diaphyseal fractures of the humerus. A randomised controlled study. Int Orthop. 2007; 31(3):391-395.

18. Lin J, Hou SM. Antegrade locked nailing for humeral shaft fractures. CORR, No.365, August, 1999, 201-210.

19. Lin J. Treatment of humeral shaft fractures with humeral locked nailing and comparison with plate fixation. J Trauma. 1998; 44:859-64.

20. Garnal Hosny, Abdel Maksood MD et al. Interlocking Nailing Versus Plating of Humeral shaft Fractures, Pan Arab f. Orth. of Trauma.

21. Ingman AM, Waters DA. Locked intramedullary nailing of humeral shaft fractures-implant design, surgical techniques and clinical results. JBJS, 1994, 76-B(1):2329.

22. Flinkkilä T, Hyvönen $\mathrm{P}$ et al. Recovery of shoulder joint function after humeral shaft fracture, a comparative study between antegrade intramedullary nailing and plate fixation. Arch Orthop Trauma Surg. 2004; 124(8):53741.

23. Singisetti K, Ambedkar M. Nailing versus plating in humerus shaft fractures: A prospective comparative study. Int Orthop. 2010; 34(4):571-576

24. Bhandari M, Devereaux PJ. Compression plating versus intramedullary nailing of humeral shaft fractures-a meta-analysis. Acta Orthop. 2006; 77(2):279-284.

25. Bolano LE, Iaquinto JA, Vasicek V. Operative treatment of humerus shaft fractures: A prospective randomized study comparing intramedullary nailing with dynamic compression plating. Presented at the Annual Meeting of the American Academy of Orthopaedic Surgeons, 1995.

26. Holstein A, Lewis GM. Fractures of the humerus with radial nerve paralysis. JBJS Am. 1963; 45A:1382-1388. 